\title{
Article \\ The Response Regulator FlmD Regulates Biofilm Formation in Comamonas testosteroni through the Transcriptional Activator SoxR
}

\author{
Yunhao Wang ${ }^{1,2,3} \mathbb{D}^{\text {, Zhou Huang }}{ }^{1,2}$, Nan Zhou ${ }^{1}$, Chang Liu ${ }^{1}$, Chengying Jiang ${ }^{1,2}$, Defeng Li ${ }^{1,2}$ \\ and Shuangjiang Liu 1,2,4,*
}

check for

updates

Citation: Wang, Y.; Huang, Z.; Zhou,

N.; Liu, C.; Jiang, C.; Li, D.; Liu, S.

The Response Regulator FlmD

Regulates Biofilm Formation in

Comamonas testosteroni through the

Transcriptional Activator SoxR.

Microorganisms 2022, 10, 356.

https://doi.org/10.3390/

microorganisms10020356

Academic Editor: Romain Briandet

Received: 24 December 2021

Accepted: 2 February 2022

Published: 4 February 2022

Publisher's Note: MDPI stays neutral with regard to jurisdictional claims in published maps and institutional affiliations.

Copyright: (C) 2022 by the authors. Licensee MDPI, Basel, Switzerland. This article is an open access article distributed under the terms and conditions of the Creative Commons Attribution (CC BY) license (https:// creativecommons.org/licenses/by/ $4.0 /)$.
1 State Key Laboratory of Microbial Resources, Institute of Microbiology, Chinese Academy of Sciences, Beijing 100101, China; wangyh@mail.hzau.edu.cn (Y.W.); huangzhou_129@msn.com (Z.H.); joel.c@126.com (N.Z.); LIUC@IM.AC.CN (C.L.); jiangcy@im.ac.cn (C.J.); lidefeng@im.ac.cn (D.L.)

2 College of Life Sciences, University of Chinese Academy of Sciences, Beijing 100049, China

3 College of Resources and Environment, Huazhong Agricultural University, Wuhan 430070, China

4 State Key Laboratory of Microbial Biotechnology, Shandong University, Qingdao 266237, China

* Correspondence: liusj@im.ac.cn or liusj@sdu.edu.cn; Tel.: +86-10-64807423

\begin{abstract}
Biofilm formation is a survival strategy by which microorganisms adapt to environmental challenges. It is regulated by various signals, such as the second messenger $c$-di-GMP. We previously found that the Flm chemosensory pathway could respond to chemical signals and regulate biofilm formation. This regulation is independent of $c$-di-GMP. A previous study revealed that the response regulator FlmD is involved in biofilm formation; however, how chemical signals are transmitted downstream of FlmD remained unclear. In the present study, transcriptome analysis and gel shift assay reveal that SoxR, a transcriptional activator of the efflux transporter acr $A B$-tolC operon, mediates the downstream signaling of FlmD. Phosphorylated FlmD interacts with SoxR and disrupts the interaction between SoxR and the acr $A B$-tolC operon. It causes a decrease in the expression of $a c r A B$ tolC operon. The downregulation of $a c r A, a c r B$, or tolC gene expression results in making less biofilm formation. In conclusion, we identified that the transcription regulator SoxR plays a role in the c-di-GMP independent regulation of biofilm formation in Comamonas testosteroni.
\end{abstract}

Keywords: biofilm formation; chemosensory pathway; response regulator; efflux pump; transcriptional activator SoxR; Comamonas testosteroni

\section{Introduction}

Biofilm formation is a process in which microbial cells attach and aggregate on surfaces to form a structured multicellular community [1]. Microbial biofilm helps microbial cells protect themselves from environmental stresses and plays key roles in chronic infections, biocorrosion, and bioremediation [2-5]. Chemotaxis is another strategy for microbial adaptation to new environments. Compared with sessile cells in biofilm, chemotactic cells swim and live in a planktonic state. Chemotaxis enables bacteria to migrate toward favorable niches or to move away from unfavorable ones [6]. Extensive research has revealed that the transition between planktonic and sessile modes of microbial life requires precise and efficient regulation mediated by signaling pathways. Our previous study revealed that two chemosensory pathways coordinate via signal cross-talking for regulation between biofilm formation and chemotaxis in Comamonas testosteroni [7].

The chemosensory pathway is a specialized form of two-component system [8]. The key elements of chemosensory pathways are a histidine kinase and a cognate response regulator. However, the histidine kinases of chemosensory pathways receive signals from chemoreceptors and lack signal sensing domains [9]. The chemosensory system of Escherichia coli has been well studied as a model; it has five chemoreceptors and only one chemosensory pathway for chemotaxis [10]. Genome analyses have revealed many 
homologous chemosensory systems, which are often more complex in terms of the number and diversity of chemosensory signaling proteins in other bacterial and archaeal species [11]. Importantly, studies have shown that not all pathways are involved in chemotaxis, but have other functions [9]. Phylogenomic clustering has revealed that chemosensory pathways could be classified into three principal functional classes, namely those associated with flagellar motility (the F class, which can be divided into 17 subclasses, F1-F17), Tfp-based motility (the Tfp class), and alternative (non-motility) cellular functions (the ACF class) [12].

Comamonas species are widely distributed in soil, sediments, and garden ponds [13]. Because they miss essential genes for hexose phosphorylation, these species do not grow with glucose as a sole carbon source but metabolize organic acids and aromatic compounds $[14,15]$. C. testosteroni strains play major roles in the bioremediation of contaminated environments and the biological geo-cycling of nutrients. C. testosteroni strain CNB-1 has 19 chemoreceptor genes and two chemosensory clusters (che and flm) [16-18]. The che cluster belongs to the F7 class and is involved in chemotaxis. The flm cluster belongs to the Tfp class but cannot modulate type IV pilus-mediated motility. In a previous study, we demonstrated that $\mathrm{flm}$ cluster is involved in biofilm formation, and that there is a cross-talk between che and flm clusters. More interestingly, the cross-talk, which is mediated through the kinase CheA and phosphorylation of response regulator FlmD, could coordinate these two cell processes: chemotaxis and biofilm formation [7].

It is well known that the second messenger $3^{\prime}, 5^{\prime}$-cyclic diguanylic acid (c-di-GMP) is a key regulator of biofilm formation. High intracellular $c$-di-GMP concentrations facilitate the transition of bacterial cells from a planktonic state to a sessile one and support biofilm formation [19]. The response regulator WspR of the Wsp pathway, belonging to the ACF class, has a diguanylate cyclase domain (GGDEF) and produces $c$-di-GMP to regulate biofilm formation in the genus Pseudomonas [20-22]. Unlike WspR, FlmD is a typical single-domain response regulator without an additional GGDEF domain and thus cannot respond by producing c-di-GMP. PilH of the Chp/Pil pathway in P. aeruginosa is a response regulator homologous to FlmD; it is involved in twitching motility and cAMP-dependent virulence systems (Vfr) [23,24]. However, neither the adenylate cyclase homologue $\mathrm{CyaB}$ producing cAMP nor the master transcriptional regulator $\mathrm{Vfr}$ could be found in $C$. testosteroni. Thus, the mechanism by which FlmD regulates biofilm formation remained unknown. In this study, we aim to explore the signal transduction of Flm pathway involved in biofilm formation.

\section{Materials and Methods}

\subsection{Bacterial Strains and Plasmids}

The bacterial strains and plasmids used in this study are listed in Table 1. C. testosteroni and its mutants were cultivated and maintained at $30{ }^{\circ} \mathrm{C}$ in Luria-Bertani (LB) broth or on LB plates with $1.5 \%(w / v)$ agar, and kanamycin was used at $150 \mu \mathrm{g} / \mathrm{mL}$ (broth) or $200 \mu \mathrm{g} / \mathrm{mL}$ (plates) when needed. The E. coli strains were cultivated at $37^{\circ} \mathrm{C}$ in LB broth or on LB plates with $1.5 \%(w / v)$ agar and kanamycin was used at $50 \mu \mathrm{g} / \mathrm{mL}$ when needed. Genetic disruption and complementation in CNB-1 were conducted using pK18mobSacB and pBBR1MCS-2, respectively (Table 1).

\subsection{Transcriptome Analysis by RNA-Seq}

Samples were cultivated in 6-well plates with duplicates and collected after incubation at $30^{\circ} \mathrm{C}$ until reaching the stationary phase. Duplicates were made for each strain. Library construction and sequencing were performed by the Illumina HiSeq platform, and paired-end reads were generated (Novogene, Beijing, China). The sequence reads were mapped, and the expression analysis application was conducted using Bowtie 2 and DESeq $[27,28]$. Genes with an adjusted $p$-value $<0.05$ found by DESeq were considered differentially expressed. 
Table 1. Strains and plasmids used in this study.

\begin{tabular}{|c|c|c|}
\hline Strain/Plasmid & Relevant Genotype or Description & Sources \\
\hline \multicolumn{3}{|l|}{ Strains } \\
\hline \multicolumn{3}{|l|}{ Comamonas testosteroni } \\
\hline CNB-1 & & [25] \\
\hline CNB- $1 \Delta f l m D$ & FlmD (CtCNB1_3988) disrupted in CNB-1 & [7] \\
\hline CNB-1 $\Delta d h l C$ & DhlC (CtCNB1_0516) disrupted in CNB-1 & This study \\
\hline CNB-1 $\triangle a n s P$ & AnsP (CtCNB1_0951) disrupted in CNB-1 & This study \\
\hline CNB-1 $\triangle$ CtCNB1_0381 & CtCNB1_0381 disrupted in CNB-1 & This study \\
\hline CNB-1 $\triangle a c r \bar{A}$ & AcrA (CtCNB1_0177) disrupted in CNB-1 & This study \\
\hline CNB-1 $\Delta a c r B$ & AcrB (CtCNB1_0178) disrupted in CNB-1 & This study \\
\hline CNB-1 1 tolC & TolC (CtCNB1_0179) disrupted in CNB-1 & This study \\
\hline CNB- $1 \Delta \operatorname{soxR}$ & SoxR (CtCNB1_0176) disrupted in CNB-1 & This study \\
\hline \multicolumn{3}{|l|}{ Escherichia coli } \\
\hline & $\mathrm{F}^{-} \varphi 80 \mathrm{~d}$ lacZ $\Delta \mathrm{M} 15 \Delta(\mathrm{lacZYA}-\arg \mathrm{F}) \mathrm{U} 169$ recA1 endA1 & \\
\hline $\mathrm{DH} 5 \alpha$ & $\begin{array}{c}\text { hsdR17 }\left(\mathrm{r}_{\mathrm{K}}^{-} \mathrm{m}_{\mathrm{K}}^{+}\right) \text {supE44 } \lambda \text { - thi-1 gyrA96 relA1 phoA; host for } \\
\text { DNA manipulations }\end{array}$ & TransGen \\
\hline BL21(DE3) & $\mathrm{F}^{-}$ompT hsdS $\left(\mathrm{r}_{\mathrm{B}}^{-} \mathrm{m}_{\mathrm{B}}^{-}\right)$gal dcm (DE3) & Novagen \\
\hline XL1-Blue & $\begin{array}{c}\text { MRF' Kan, glycerol stockb } \\
\text { (host strain for propagating pBT and pTRG recombinants) }\end{array}$ & Stratagene \\
\hline \multicolumn{3}{|l|}{ Plasmids } \\
\hline pBBR1MCS-2 & $\mathrm{Km}^{\mathrm{r}}$, lacPOZ' broad host vector with $\mathrm{R}$ type conjugative origin & [26] \\
\hline pBBR1MCS2-flmD & Carries $f l m D$ to generate complementation & [7] \\
\hline pBBR1MCS2-flmDD55A & A mutation from an aspartate to an alanine in 55th residue & [7] \\
\hline pBBR1MCS2-flmDD12K & A mutation from an aspartate to a lysine in 12 th residue & This study \\
\hline pBBR1MCS2-soxR & Carries soxR to generate complementation & This study \\
\hline pBBR1MCS2-acrA & Carries $a c r A$ to generate complementation & This study \\
\hline pBBR1MCS2-acrB & Carries $a c r B$ to generate complementation & This study \\
\hline pBBR1MCS2-tolC & Carries tolC to generate complementation & This study \\
\hline pBBR1MCS2-soxR-his & pBBR1MCS2 derivative for expression of SoxR & This study \\
\hline pBBR1MCS2-flmDD12K-sterp + soxR-his & $\begin{array}{l}\text { pBBR1MCS2 derivative for co-purification of SoxR } \\
\text { and FlmDD12K }\end{array}$ & This study \\
\hline pBBR1MCS2-flmDD55A-sterp + soxR-his & $\begin{array}{c}\text { pBBR1MCS2 derivative for co-purification of SoxR } \\
\text { and FlmDD55A }\end{array}$ & This study \\
\hline pBBR1MCS2pfer & adds a strong constitutive promoter in pBBR1MCS-2 & [7] \\
\hline pBBR1MCS2pfer-flmD & Carries $f l m D$ to overexpression & [7] \\
\hline $\mathrm{pET} 28 \mathrm{a}$ & $\mathrm{Km}^{\mathrm{r}}$, bacterial expression vector with a His-tag & Youbio \\
\hline pET28a-flmD & pET28a derivative for expression of FlmD & [7] \\
\hline pET28a-flmDD55A & pET28a derivative for expression of FlmD with D55A mutation & This study \\
\hline pET28a-flmDD12K & pET28a derivative for expression of FlmD with D12K mutation & This study \\
\hline $\mathrm{pBT}$ & Bacterial two-hybrid bait plasmid with $\lambda$ repressor protein $\left(\lambda_{c} \mathrm{I}\right)$ & Stratagene \\
\hline pBT-cheA & pBT derivative with $\lambda_{\mathrm{cI}}$ linked to CheA & [7] \\
\hline pBT-flmDD12K & pBT derivative with $\lambda_{c I}$ linked to FlmDD12K & This study \\
\hline pBT-flmDD55A & pBT derivative with $\lambda \mathrm{cI}$ linked to FlmDD55A & This study \\
\hline pTRG & $\begin{array}{l}\text { Bacterial two-hybrid bait plasmid with } \alpha \text {-subunit of RNA } \\
\text { polymerase (RNAp) }\end{array}$ & Stratagene \\
\hline pTRG-cheW & pTRG derivative with RNAp linked to CheW & [7] \\
\hline pTRG-soxR & pTRG derivative with RNAp linked to SoxR & This study \\
\hline
\end{tabular}

\subsection{Reverse Transcription PCR (RT-PCR) and Quantitative Reverse Transcription PCR (RT-qPCR)}

Samples for reverse transcription were cultured in LB at $30^{\circ} \mathrm{C}$ and collected after incubation until reaching the stationary phase. Total RNA was extracted by Bacterial RNA Kit (Omega, Norcross, GA, USA). Genomic DNA was removed and cDNA was synthesized by HiFiScript gDNA Removal cDNA Synthesis Kit (CWBIO, Beijing, China). The remaining steps of RT-PCR are the same as PCR. The RT-qPCRs were performed in the LightCycler 480 instrument (Roche, Basel, Switzerland) with KAPA SYBR FAST Universal qPCR Kit (Merck, Kenilworth, IL, USA). 
To detect and quantify transcript levels of target genes, primers were designed to amplify about 200 bp region of each gene (RT16sRNA-F: 5'-gcggctgatggcagatta-3'; RT16sRNA-R: 5'-ttacaacccgagggcctt-3'; RT0176-F: 5'-actgaggatgatccgctg-3'; RT0176-R: 5'cgatctcctccagcgtga-3'; RT0177-F: 5'-cgaggaggccgatacaag-3'; RT0177-R: $5^{\prime}$-cgaaaccagggtggtcag3'; RT0178-F: 5'-gccgtgatgctggtgttt-3'; RT0178-R: 5'-caggatcgcgttcttgca-3'; RT0179-F: 5'gctgggagctggatctgt-3'; RT0179-R: $5^{\prime}$-tcgtgtcctgctgattgg- $\left.3^{\prime}\right)$. The qPCR run protocol was: pre-incubation $\left(5 \mathrm{~min}\right.$ at $\left.95^{\circ} \mathrm{C}\right), 40$ amplification cycles $\left(10 \mathrm{~s}\right.$ at $95^{\circ} \mathrm{C} ; 20 \mathrm{~s}$ at $55^{\circ} \mathrm{C} ; 25 \mathrm{~s}$ at $72{ }^{\circ} \mathrm{C}$ ), and melting curve (from 55 to $97^{\circ} \mathrm{C}$ ). Transcript levels were determined using the comparative CT (threshold cycle) method of relative quantification. All samples have the same 16s rRNA, so the 16S rRNA gene transcripts were established as the internal control reference gene for relative $\mathrm{mRNA}$ quantification.

\subsection{Biofilm Formation Assays and Growth Measurement}

Biofilm formation assay was performed as previously described [7]. C. testosteroni was cultured in LB overnight, and then cultures were diluted to an $\mathrm{OD}_{600}=1.5 .100 \mu \mathrm{L}$ of the diluted sample was added to a PVC multi-well plate (Corning, Corning, NY, USA), which had been sterilized by UV. Samples were incubated at $30{ }^{\circ} \mathrm{C}$ in a humidified incubator for $48 \mathrm{~h}$. Planktonic cells were removed carefully by pipettes, and plates were washed with sterile phosphate buffered saline (PBS) three times. Next, $125 \mu \mathrm{L}$ of crystal violet $(0.1 \%)$ were added into the wells and incubated for $30 \mathrm{~min}$. After three washes, $150 \mu \mathrm{L} \mathrm{of} 30 \%$ acetic acid was added to dissolve the crystal violet and incubated for $10 \mathrm{~min}$. The $\mathrm{OD}_{590}$, as the parameter of biofilm biomass, was measured on a multi-well plate reader Victor Nivo (PerkinElmer, Waltham, MA, USA). The growth $\left(\mathrm{OD}_{600}\right)$ of $\mathrm{CNB}-1$ wild-type and mutant strains was measured in LB by using an automated growth curve analysis system (Bioscreen, Turku, Finland).

\subsection{Genetic Cloning, Overexpression, and Protein Purification}

Genes flmD and its mutants (flmDD12K and $f l m D D 55 A$ ) were cloned into pET28a and transformed to $E$. coli BL21 (DE3) to generate a C-terminal his-tagged fusion protein. The expression of these genes was induced by the addition of $0.3 \mathrm{mM} \mathrm{IPTG}$ at $16^{\circ} \mathrm{C}$ for $12 \mathrm{~h}$. Initially, we also used E. coli to express and purify the protein SoxR, but failed. Considering SoxR is a transcription factor that might disrupt the normal cellular activity of E. coli, C. testosteroni replaced E. coli as the protein SoxR expression system. Gene soxR with a His-tag sequence was cloned into pBBR1MCS-2 and transformed to C. testosteroni strain to generate the target protein. There was an interaction between SoxR and FlmD (see the Results section for details), FlmD could be co-purified with SoxR. So, we used C. testosteroni CNB- $1 \Delta$ flmD instead of $C$. testosteroni CNB-1 to obtain pure SoxR and exclude the influence from FlmD on subsequent experiments. C. testosteroni was cultured in LB overnight, and then cells were harvested for SoxR purification. All proteins were then purified using AKTA FPLC equipped with a HisTrap HP column. Buffer desalting and protein concentration were performed by an Amicon Ultra-15 concentrator (Merck, Kenilworth, IL, USA).

\subsection{Gel Shift Assay (EMSA)}

Gel shift assay was performed for studying gene regulation and determining proteinDNA interactions. DNA probes were prepared by PCR using $5^{\prime}$-FAM-labeled primers: for probe1, probe- $\mathrm{F}\left(5^{\prime}\right.$-atggactctcccagaatgaatgcgccc- $\left.3^{\prime}\right)$ and probe1-R $\left(5^{\prime}\right.$-gatgtcttctccggggcttgact$\left.3^{\prime}\right)$; for probe2, probe-F (5'- atggactctcccagaatgaatgcgccc- $\left.3^{\prime}\right)$ and probe2-R $\left(5^{\prime}\right.$ - acctgccaatgcttg tcacaagcc- $\left.3^{\prime}\right)$. The SoxR and FlmD/FlmD variant proteins were purified as described above. Thirty-five ng of the labeled probe were incubated with various amounts of purified SoxR and FlmD/FlmD variants for binding rection in $20 \mu \mathrm{L}$ of binding buffer $20 \mathrm{mM}$ Tris- $\mathrm{HCl}$ (pH 7.8), $1 \mathrm{mM} \mathrm{MgCl}$, $40 \mathrm{mM} \mathrm{KCl,} 2 \mathrm{mM}$ DTT, $0.1 \mathrm{mg} / \mathrm{mL}$ bovine serum albumin (BSA), and 5\% glycerol] for $20 \mathrm{~min}$ at room temperature. The binding mixture was separated from free DNA by electrophoresis through a $6 \%$ native polyacrylamide gel at $80 \mathrm{~V}$ at $4{ }^{\circ} \mathrm{C}$ in $0.5 \times$ TBE running buffer (44.5 mM Tris, $44.5 \mathrm{mM}$ Boric acid, $1 \mathrm{mM}$ EDTA, 
$\mathrm{pH}=8.0$ ). The gels were exposed to chemiluminescence imaging screens for quantitative analysis with Tanon-5200Multi (Tanon, Shanghai, China).

\subsection{Protein Co-Purification}

A protein-protein interaction study was performed as previously described by minor adjustments [29]. Gene $f l m D$ mutant ( flmDD12K or $f l m D D 55 A$ ) with a strep-tag and gene soxR with a his-tag were both cloned into pBBR1MCS2 and transformed to $C$. testosterni CNB-1 $\Delta f l m D$ for affinity chromatography with StrepTactin Sepharose. The role of FlmD with C-terminal strep-tag is as the bait protein to obtain proteins that interact with FlmD in vivo. Moreover, strep-tag and his-tag could be detected by specific antibodies and were used for protein detection in western blotting. C. testosteroni was cultured in LB overnight, and then cells were harvested by centrifugation for $20 \mathrm{~min}$ at $3000 \times g$ at $4{ }^{\circ} \mathrm{C}$ and washed twice with the phosphate buffered saline (PBS). The cells were resuspended at a ratio of $10 \mathrm{~mL}$ of buffer per $1 \mathrm{~g}$ of wet weight in the PBS $(\mathrm{pH}=7.0)$. The cell suspension was lysed twice by using an ultrasonic cell disrupter (SCIENTZ, Ningbo, China). Subsequently, lysates were centrifuged at $10,000 \times g$ for $15 \mathrm{~min}$ to remove insoluble material. The solubilized proteins were incubated with streptavidin beads (Biodragon, Suzhou, China) for $1 \mathrm{~h}$ at $4{ }^{\circ} \mathrm{C}$. The beads were pelleted by centrifugation for $1 \mathrm{~min}$ at $3000 \times \mathrm{g}$ at $4{ }^{\circ} \mathrm{C}$ and washed five times with PBS to remove unbound proteins. Finally, protein binding to streptavidin beads was analyzed by SDS-PAGE and detected by western blotting.

\subsection{Bacterial Two-Hybrid Assay}

The Bacterial two-hybrid system (Agilent, Santa Clara, CA, USA) was used to test the interaction between SoxR and FlmD variants. Plasmid construction and screening were performed according to the manufacturer's instructions. The pBT and pTRG vectors containing genes of SoxR and FlmD variants were generated. Co- transformants (E. coli XL1-Blue strain) containing both $\mathrm{pBT}$ and $\mathrm{pTRG}$ derivatives were cultured overnight. These cultures were collected and washed by $\mathrm{ddH}_{2} \mathrm{O}$ three times. Three $\mu \mathrm{L}$ bacterial suspensions were inoculated on selective screening medium plate containing $5 \mathrm{mM} 3$-amino-1,2,4-triazole (3-AT), $12.5 \mu \mathrm{g} / \mathrm{mL}$ streptomycin, $15 \mu \mathrm{g} / \mathrm{mL}$ tetracycline, and $25 \mu \mathrm{g} / \mathrm{mL}$ chloramphenicol at $37^{\circ} \mathrm{C}$ for $36 \mathrm{~h}$. The better growth of transformants indicates a stronger interaction.

\subsection{Sequence Alignment and Analysis}

Domains of FlmD were identified and annotated through SMART (SMART: Main page (embl.de, accessed on 29 September 2020) [30]. Promoter and transcription factor (TF) binding sites were predicted through BDGP program (BDGP: Neural Network Promoter Prediction (fruitfly.org, accessed on 29 September 2020) and BPROM program (BPROMPrediction of bacterial promoters (softberry.com, accessed on 29 September 2020) [31,32]. Multiple sequence alignment was performed by MAFFT online service (MAFFT alignment and NJ/UPGMA phylogeny (cbrc.jp, accessed on 29 September 2020), and the result was visualized by Jalview [33,34].

\subsection{Statistical Analysis}

Statistical analysis was performed using the SigmaPlot 14.0 (Systat Software, Berkshire, UK) program. The biofilm formation was characterized by biofilm biomass with the calculation of means and standard deviations. The statistical significances of differences in biofilm formation between the wild-type and mutant strains were evaluated using Student's $t$-test (for normal data) or rank-sum test (for nonnormal data), and differences with $p$-value $<0.05$ were considered to be statistically significant. The comparative data derived from transcriptome analysis were calculated by DESeq [28], and genes with an adjusted $p$-value $<0.05$ were considered differentially expressed. 


\section{Results}

\subsection{Certain Transporter Genes Regulated by FlmD}

As mentioned above, the Flm pathway regulates biofilm formation in C. testosteroni. However, it differs significantly from any known chemosensory pathways mediating biofilm formation. Considering the key role of FlmD in biofilm formation, we performed transcriptome analysis among the wild-type strain (CNB-1), FlmD-deleted mutant strain $(\mathrm{CNB}-1 \Delta \mathrm{flmD})$, and FlmD-overexpressing strain (CNB-1/OvflmD) (Figure 1A,B) and attempted to identify the microbial process that was affected by FlmD. Compared with CNB-1, 359 genes in CNB-1 $\triangle$ flmD (Figure 1A) and 307 genes in CNB-1/OvflmD (Figure 1B) showed significant changes $(p<0.05)$. As shown in Table 2 , only 39 genes showed $>2$-fold change in $\mathrm{CNB}-1 \Delta \mathrm{flmD}$; these genes were upregulated. Hence, we speculated that FlmD negatively affected the transcription of these genes. Gene ontology (GO) enrichment analysis was performed to understand the functions of these regulated genes in biological processes. The results revealed cellular process and cross-membrane transport to be significantly affected (Figure 1C). In CNB-1/OvflmD, 26 genes exhibited >2-fold change, of which 23 genes were downregulated (Table 3). Consistent with flmD deletion, most of these 26 genes are involved in material transport in CNB-1/OvflmD (Figure 1D).

Table 2. Genes that show significant and $>2$-fold change at the transcriptional level in C. testosteroni strain CNB-1 $\Delta$ flmD.

\begin{tabular}{|c|c|c|c|c|}
\hline Gene & Locus_Tag & Annotations & Padj & log2FoldChange \\
\hline hmp & CtCNB1_0015 & ferredoxin & $2.39 \times 10^{2}$ & 1.1233 \\
\hline boxA & CtCNB1_0065 & benzoyl-CoA oxygenase & $3.01 \times 10^{3}$ & 1.5735 \\
\hline$b \circ x B$ & CtCNB1_0066 & benzoyl-CoA oxygenase & $3.81 \times 10^{13}$ & 1.6828 \\
\hline boxc & CtCNB1_0067 & benzoyl-CoA-dihydrodiol lyase & $3.08 \times 10^{6}$ & 1.2693 \\
\hline livK1 & CtCNB1_0096 & $\mathrm{ABC}$ transporter permease & $6.45 \times 10^{7}$ & 1.249 \\
\hline$b C L$ & CtCNB1_0097 & 4-hydroxybenzoate-CoA ligase & $2.09 \times 10^{6}$ & 1.1543 \\
\hline $\operatorname{tau} A$ & CtCNB1_0160 & ABC transporter permease & $1.48 \times 10^{9}$ & 1.2986 \\
\hline $\tan C$ & CtCNB1_0161 & ABC transporter permease & $8.38 \times 10^{4}$ & 1.1119 \\
\hline $\operatorname{acr} A$ & CtCNB1_0177 & RND family efflux transporter MFP subunit & $9.97 \times 10^{8}$ & 1.0644 \\
\hline tolC & CtCNB1_0179 & RND transporter & $1.74 \times 10^{6}$ & 1.2098 \\
\hline CtCNB1_0381 & CtCNB1_0381 & hypothetical protein & $4.06 \times 10^{3}$ & 1.108 \\
\hline caiD & CtCNB1_0392 & enoyl-CoA hydratase & $1.77 \times 10^{7}$ & 1.0308 \\
\hline$g p m B$ & CtCNB1_0417 & phosphoglycerate mutase & $2.67 \times 10^{2}$ & 1.0422 \\
\hline dhlC & CtCNB1_0516 & SSS sodium solute transporter superfamily protein & $2.94 \times 10^{4}$ & 1.1811 \\
\hline araj & CtCNB1_0518 & major facilitator transporter & $3.17 \times 10^{4}$ & 1.4008 \\
\hline ansP & CtCNB1_0951 & proline-specific permease & $5.09 \times 10^{5}$ & 1.6276 \\
\hline $\operatorname{dad} A$ & CtCNB1_0952 & amino acid dehydrogenase & $4.35 \times 10^{4}$ & 1.0916 \\
\hline $\operatorname{livK} 2$ & CtCNB1_1147 & twin-arginine translocation pathway signal protein & $1.94 \times 10^{3}$ & 1.2937 \\
\hline eutG & CtCNB1_1590 & 4-hydroxybutyrate dehydrogenase & $2.33 \times 10^{3}$ & 1.1806 \\
\hline CtCNB1_2363 & CtCNB1_2363 & hypothetical protein & $1.15 \times 10^{2}$ & 1.0003 \\
\hline $\operatorname{sox} \bar{X}$ & CtCNB1_2868 & SoxX protein & $3.36 \times 10^{2}$ & 1.0829 \\
\hline SoxA & CtCNB1_2869 & SoxA protein & $4.58 \times 10^{3}$ & 1.0581 \\
\hline $\operatorname{sox} Y$ & CtCNB1_2871 & twin-arginine translocation pathway signal & $2.94 \times 10^{4}$ & 1.1995 \\
\hline soxD & CtCNB1_2872 & cytochrome $\mathrm{C}^{\mathrm{I}}$ & $2.07 \times 10^{5}$ & 1.3067 \\
\hline CtCNB1_3408 & CtCNB1_3408 & hypothetical protein & $2.02 \times 10^{2}$ & 1.1134 \\
\hline $\operatorname{dct} P$ & CtCNB1_3427 & TRAP dicarboxylate transporter, DctP subunit & $2.54 \times 10^{18}$ & 1.1641 \\
\hline$i l v D$ & CtCNB1_3428 & phosphogluconate dehydratase & $3.83 \times 10^{11}$ & 1.1086 \\
\hline eda & CtCNB1_3429 & keto-deoxy-phosphogluconate aldolase & $2.26 \times 10^{7}$ & 1.4534 \\
\hline $\operatorname{livK3}$ & CtCNB1_3479 & $\mathrm{ABC}$ transporter permease & $2.97 \times 10^{3}$ & 1.097 \\
\hline $\operatorname{sapF}$ & CtCNB1_3509 & ABC-type antimicrobial peptide & $1.39 \times 10^{3}$ & 1.2249 \\
\hline $\operatorname{cox} L$ & CtCNB1_3514 & carbon monoxide dehydrogenase & $9.86 \times 10^{3}$ & 1.1075 \\
\hline $\operatorname{cox} S$ & CtCNB1_3515 & carbon monoxide dehydrogenase & $3.64 \times 10^{2}$ & 1.079 \\
\hline$i l v B$ & CtCNB1_4060 & thiamine pyrophosphate-requiring enzymes & $3.64 \times 10^{3}$ & 1.0155 \\
\hline$a p b A$ & CtCNB1_4061 & 2-dehydropantoate 2-reductase & $1.80 \times 10^{2}$ & 1.4053 \\
\hline$t c t C$ & CtCNB1_4499 & $\mathrm{ABC}$ transporter substrate-binding protein & $9.44 \times 10^{12}$ & 1.3628 \\
\hline CtCNB1_4500 & CtCNB1_4500 & hypothetical protein & $1.07 \times 10^{5}$ & 1.6667 \\
\hline$u b i \bar{H}$ & CtCNB1_4501 & FAD-dependent oxidoreductase & $5.75 \times 10^{4}$ & 1.214 \\
\hline thiJ & CtCNB1_4569 & putative intracellular protease/amidase & $2.03 \times 10^{14}$ & 1.0617 \\
\hline $\bmod A$ & CtCNB1_4661 & extracellular solute-binding protein & $5.80 \times 10^{5}$ & 1.1208 \\
\hline
\end{tabular}



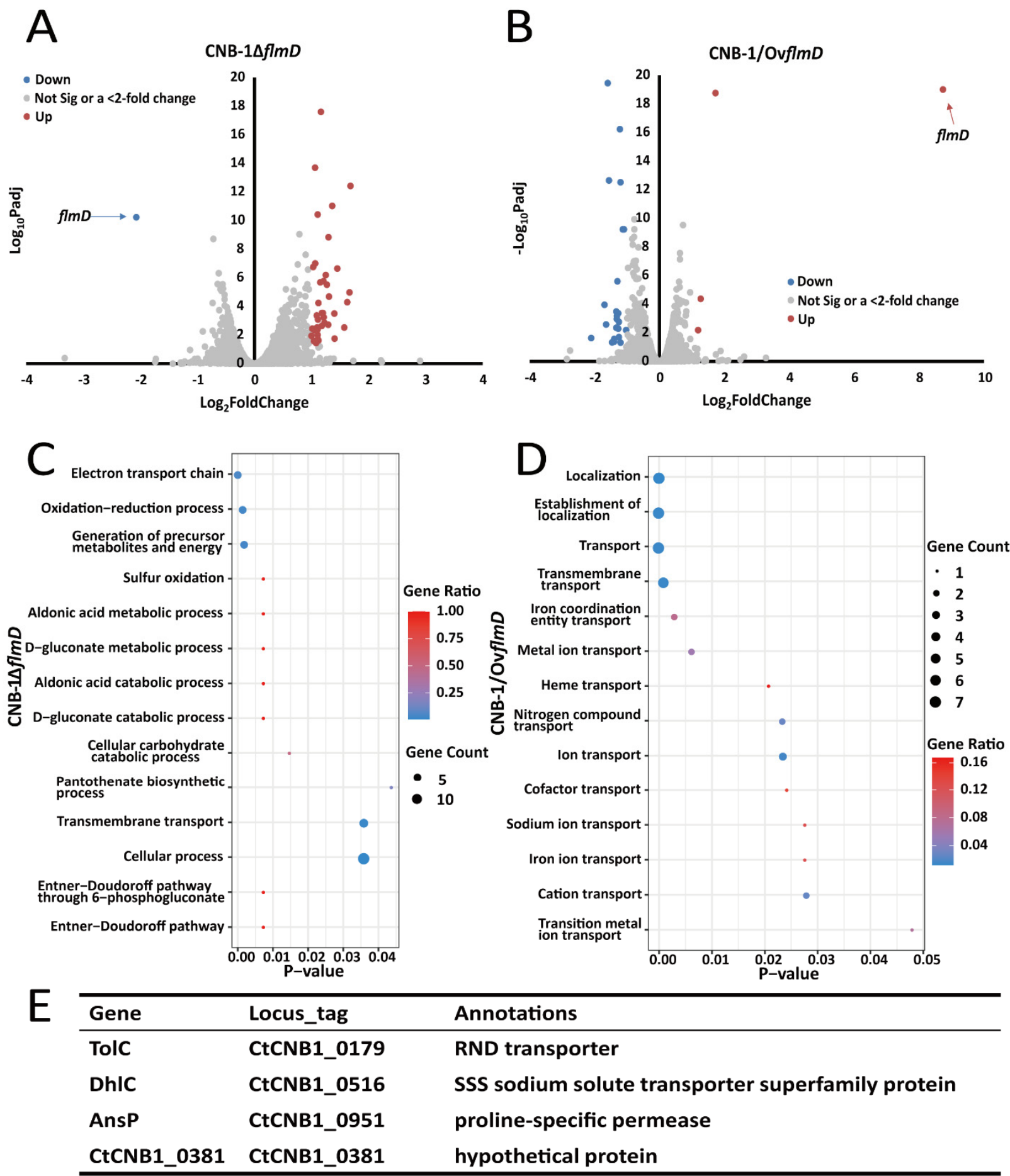

Figure 1. FlmD negatively regulates the transcription of transporters in C. testosteroni (A); and (B) Comparative transcriptome analysis among CNB-1, CNB-1 $\triangle f l m D$, and CNB-1/OvflmD revealed that FlmD negatively regulated a small number of genes. Color scheme: red dots, genes showing significant and >2-fold upregulation; gray dots, genes showing no significant or <2-fold change; and blue dots, genes showing significant and $>2$-fold downregulation. Padj: $p$-value adjusted for multiple testing with the Benjamini-Hochberg procedure to control the false discovery rate; (C) and (D) Gene ontology terms in biological process categories associated with material transport were enriched; (E) Four genes show significant and $>2$-fold change in both strains CNB-1 $\Delta$ flmD and CNB-1/OvflmD. 
Table 3. Genes that show significant and $>2$-fold change at the transcriptional level in $C$. testosteroni strain CNB-1/OvflmD.

\begin{tabular}{|c|c|c|c|c|}
\hline Gene & Locus_Tag & Annotations & Padj & log2FoldChange \\
\hline tolC & CtCNB1_0179 & RND transporter & $5.23 \times 10^{3}$ & -1.2708 \\
\hline CtCNB1_0378 & CtCNB1_0378 & hypothetical protein & $2.67 \times 10^{3}$ & -1.6453 \\
\hline CtCNB1_0381 & CtCNB1_0381 & hypothetical protein & $1.12 \times 10^{4}$ & -1.6966 \\
\hline CtCNB1_0383 & CtCNB1_0383 & hypothetical protein & $4.46 \times 10^{3}$ & -1.3307 \\
\hline$d h l \bar{C}$ & CtCNB1_0516 & SSS sodium solute transporter superfamily & $4.24 \times 10^{2}$ & -1.4034 \\
\hline ansP & CtCNB1_0951 & proline-specific permease & $1.10 \times 10^{3}$ & -1.3189 \\
\hline $\operatorname{cir} A$ & CtCNB1_1178 & TonB-dependent receptor & $6.02 \times 10^{10}$ & -1.132 \\
\hline$n r d A$ & CtCNB1_1179 & ribonucleotide reductase & $2.33 \times 10^{2}$ & -2.1049 \\
\hline hems & CtCNB1_1180 & ribonucleotide reductase & $3.54 \times 10^{20}$ & -1.5981 \\
\hline chuT & CtCNB1_1181 & $\mathrm{ABC}$ transporter substrate-binding protein & $2.26 \times 10^{13}$ & -1.5584 \\
\hline fepD & CtCNB1_1182 & hemin transport system permease protein & $2.71 \times 10^{2}$ & -1.3963 \\
\hline fepC & CtCNB1_1183 & ABC transporter & $4.39 \times 10^{4}$ & -1.2717 \\
\hline fhuE & CtCNB1_1601 & ligand-gated channel protein & $1.73 \times 10^{3}$ & -1.2529 \\
\hline cbiK & CtCNB1_1602 & TonB-dependent receptor & $2.04 \times 10^{2}$ & -1.2527 \\
\hline CtCNB1_1891 & CtCNB1_1891 & hypothetical protein & $1.77 \times 10^{19}$ & 1.7244 \\
\hline CtCNB1_1892 & CtCNB1_1892 & hypothetical protein & $4.26 \times 10^{5}$ & 1.2684 \\
\hline CtCNB1_2304 & CtCNB1_2304 & hypothetical protein & $6.55 \times 10^{3}$ & 1.1858 \\
\hline oaf $\bar{A}$ & CtCNB1_3421 & acyltransferase & $3.30 \times 10^{4}$ & -1.3331 \\
\hline $\operatorname{cox} G$ & CtCNB1_3510 & carbon monoxide dehydrogenase subunit $\mathrm{G}$ & $4.97 \times 10^{2}$ & -1.2019 \\
\hline$h p p D$ & CtCNB1_3836 & 4-hydroxyphenylpyruvate dioxygenase & $3.02 \times 10^{13}$ & -1.2022 \\
\hline CtCNB1_3837 & CtCNB1_3837 & hypothetical protein & $6.02 \times 10^{10}$ & -1.0953 \\
\hline lraI & CtCNB1_3842 & ABC-type metal ion transport system & $4.71 \times 10^{2}$ & -1.462 \\
\hline CtCNB1_3869 & CtCNB1_3869 & hypothetical protein & $6.64 \times 10^{4}$ & -1.3152 \\
\hline fep $\bar{A}$ & CtCNB1_4259 & TonB-dependent receptor & $6.55 \times 10^{3}$ & -1.0318 \\
\hline livK1 & CtCNB1_4328 & $\mathrm{ABC}$ transporter permease & $5.94 \times 10^{17}$ & -1.2227 \\
\hline livK2 & CtCNB1_4497 & $\mathrm{ABC}$ transporter permease & $2.55 \times 10^{6}$ & -1.2985 \\
\hline
\end{tabular}

Compared with the total number of genes (4890) in the CNB-1 genome, only $6.3-7.3 \%$ of genes (most of which were related to transport systems) had significant changes at the transcription level in the CNB-1 $\triangle \mathrm{flmD}$ and CNB-1/OvflmD strains. This result suggests that FlmD is a pathway-specific regulation factor. Further analysis indicated that among these genes, only four genes shared by CNB-1 $\Delta$ flmD and CNB-1/OvflmD exhibited $>2$-fold change (Figure 1E). The four genes were tolC (CtCNB1_0179), dhlC (CtCNB1_0516), ansP (CtCNB1_0951), and a hypothetical protein-encoding gene (CtCNB1_0381), named by their annotation in the COG database [35]. Sequence analysis showed that all four genes had transmembrane sequences; three genes were annotated as transporters/permeases and one was uncharacterized.

\subsection{The Effect of TolC on Biofilm Formation}

Based on the observation that the response regulator FlmD not only affected biofilm formation but also mediated the transcription of some transporter genes, we constructed gene-knockout strains to determine the impact of these transporters on biofilm formation. Compared with the wild-type strain CNB-1, the deletion of tolC (CtCNB1_0179) was found to cause a significant biofilm formation defect; however, the other three genes [dhlC (CtCNB1_0516), ansP (CtCNB1_0951), and a hypothetical protein-encoding gene (CtCNB1_0381)] did not significantly affect biofilm formation (Figure 2A). Several studies have suggested that $\mathrm{TolC}$ is an outer membrane channel, a part of the AcrAB-TolC efflux system [36,37]. The AcrAB-TolC efflux pump belongs to the resistance-nodulationdivision (RND) family transporters responsible for the efflux of many antibiotics, dyes, and detergents; it is widespread among Gram-negative bacteria [37]. The disruption of the AcrAB-TolC pump reduces biofilm formation [38-40], which agrees with our observation in CNB-1. 


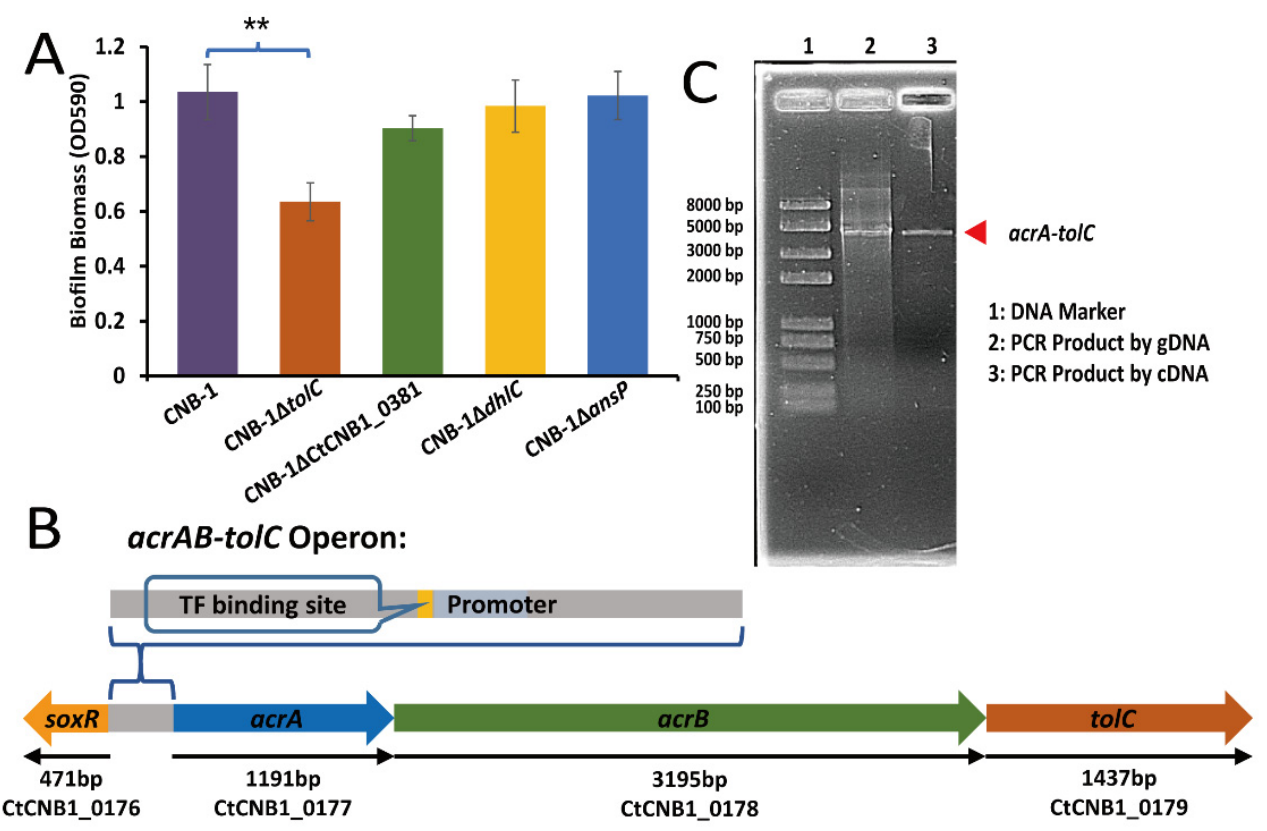

Figure 2. TolC regulates biofilm formation in C. testosteroni and belongs to the AcrAB-TolC efflux pump. (A) A crystal violet assay measured the effects of tolC, dhlC, ansP, and CtCNB1_0381 on biofilm formation. Only tolC deletion significantly reduced biofilm formation; (B) Diagram of the acrAB-tolC operon; (C) $a c r A, a c r B$, and tolC were transcribed together to form a single mRNA molecule. The gDNA of CNB-1 was a PCR template in lane 2 (as a positive control), and cDNA was a template in lane 3. Data in panel A are the means and standard deviations from three independent experiments conducted in triplicate. ${ }^{* *} p<0.01$ with Student's $t$-test).

The periplasmic membrane fusion protein AcrA and the inner membrane RND transporter AcrB, whose corresponding genes (acrA, CtCNB1_0177 and acrB, CtCNB1_0178) are located upstream of tolC in the CNB-1 genome (Figure 2B), are the other two components of the AcrAB-TolC complex [41]. These functionally related genes ( $a c r A, a c r B$, and $t o l C)$ are contiguously located on a stretch of DNA and have an operon-like structure. In addition, these genes are thought to share the same promoter, located upstream of $\operatorname{acr} A$ (Figure 2B). Therefore, $a c r A, a c r B$, and tolC may belong to the same operon. RT-PCR further confirmed this speculation. The result showed that $a c r A, a c r B$, and tolC were transcribed together to form a single messenger RNA (mRNA) molecule (Figure 2C). This observation is consistent with the gene transcription profiles of CNB- $1 \triangle f l m D$, both acrA and tolC had significant changes (more than 2-fold; $p$-value $<0.05$ ) (Table 2).

\subsection{The Transcriptional Regulation of SoxR on the acrAB-tolC Operon}

Further sequence analysis of the acrAB-tolC operon revealed that a transcription factor (TF) binding site and the transcription factor gene soxR (CtCNB1_0176, a redox-sensitive transcriptional activator) are in the upstream sequence of $a c r A, a c r B$, and tolC (Figure 2B). The $a c r A B-t o l C$ operon has a similar gene organization to the well-known lac operon and ara operon $[42,43]$. We performed RT-qPCR to determine the transcript levels of $a c r A$, acrB, and tolC in soxR mutant and wild-type strains. Compared with CNB-1, these genes showed $>2$-fold change and were downregulated in CNB-1 $\Delta \operatorname{soxR}$ (Figure 3A). In CNB-1/OvsoxR, these genes were upregulated when soxR was overexpressed (Figure 3A). In addition, based on the sequence of the predicted promoter and TF binding site, we designed probes for the gel shift assay (Figure 3B). As expected, we also observed that SoxR is bound to Probe1 DNA, which comprises a predicted promoter and TF binding site (Figure 3C). These results proved SoxR could regulate the transcription of $\operatorname{acr} A, \operatorname{acr} B$, and tolC. As SoxR is the transcription regulator of the acr $A B$-tolC operon and TolC is involved in biofilm formation, we then assessed the effect of SoxR on biofilm formation. As shown in Figure 3D, the 
deletion of soxR decreased biofilm formation. Similarly, the disruption of AcrA and AcrB significantly decreased biofilm formation (Figure 3D). Notably, however, the deletion of the corresponding genes did not affect cell growth (Supplementary Figure S1).
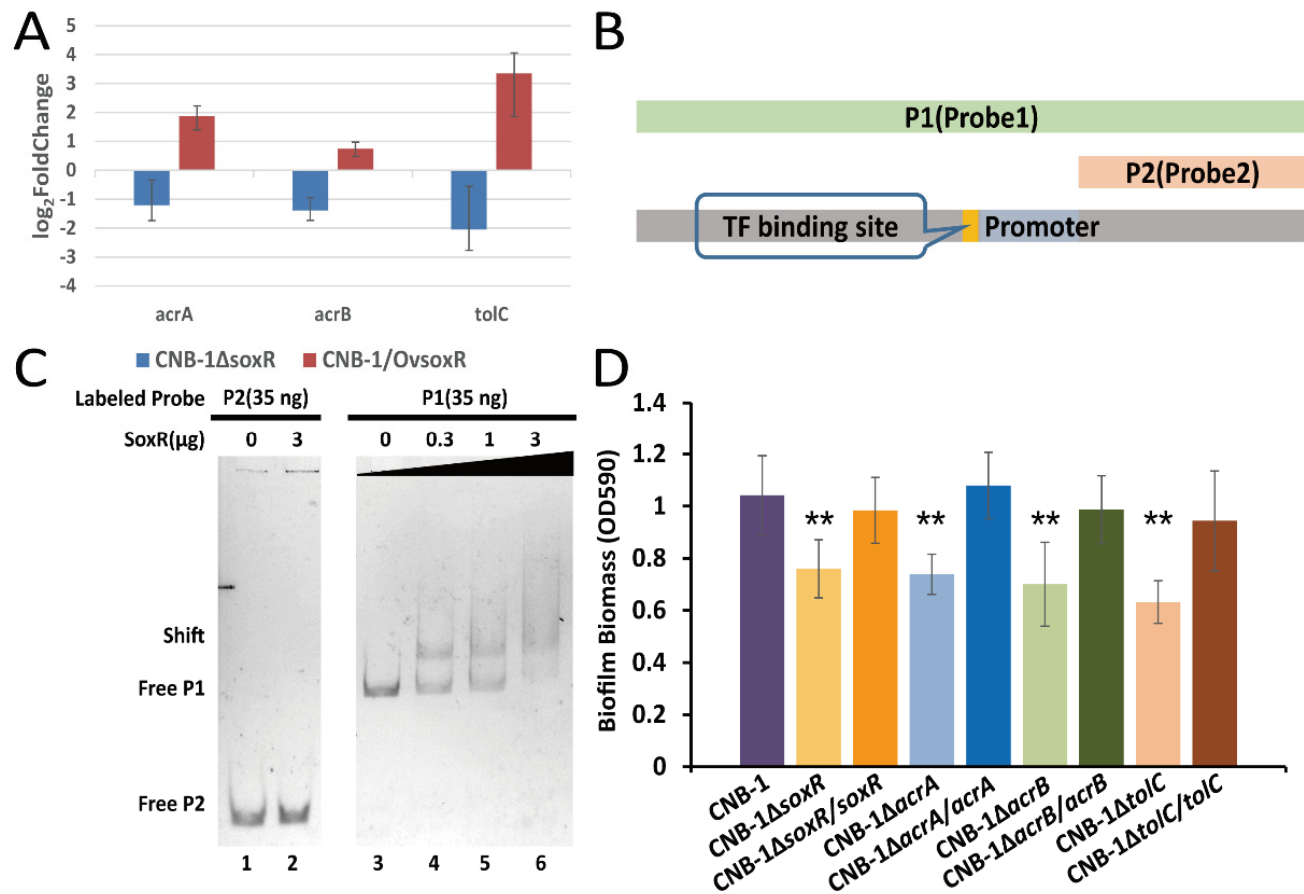

Figure 3. SoxR positively regulates the transcription of the acrAB-tolC operon in $C$. testosteroni. (A) Transcriptional changes in $a c r A, a c r B$, and tolC in soxR-deleted and soxR-overexpressing strains. (B) Diagram of probes for the gel shift assay. (C) Determination of the interaction between SoxR and acrAB-tolC operon DNA. Probe2 used as the negative control lacked predicted transcription factor binding sites and a promoter. From lanes 3 to 6, the number of Probe1 binding to proteins (shift band) increased with an increase in SoxR concentration. (D) Biofilm formation in acrAB-tolC operon components-deleted and -complemented mutant strains was assessed using a crystal violet assay. The effect of SoxR on acrAB-tolC gene transcription was consistent with that on biofilm formation. Data in panel $\mathrm{D}$ are the means and standard deviations from three independent experiments conducted in triplicate. ${ }^{* *} p<0.01$ with Student's $t$-test.).

\subsection{FlmD Variants Involved in Phosphorylation}

The phosphorylation of response regulators is important in chemosensory signal transduction. For instance, the binding of phosphorylated CheY (CheY-P) to the flagellar motor protein FliM for inducing a change in the flagellar rotation behavior is the signal output during chemotaxis. In E. coli, the CheY(D13K) variant, whose aspartic acid-13 is replaced by lysine, is equivalent to CheY-P [44,45]. The aspartate residue is conserved in response regulators of two-component systems. In addition, the phosphorylation site of response regulators is also conserved. These sites in FlmD are D12 and D55, respectively (Supplementary Figure S2). In order to measure the effect of FlmD phosphorylation, we constructed two variants: (1) FlmD(D12K), as phosphorylation activated variant, and (2) FlmD(D55A), a variant that could not be phosphorylated. As shown in Figure 4A, deletion of $f l m D(C N B-1 \Delta f l m D)$ resulted in an upregulation of biofilm formation, whereas overexpression of $\mathrm{flmD}(\mathrm{CNB}-1 / \mathrm{OvflmD})$ resulted in significant reduction of biofilm formation, indicating FlmD negatively regulates biofilm formation. The FlmD(D55A) variant lacks the phosphor-acceptor site, its related strain CNB-1 $\Delta$ flmD/flmDD55A showed enhanced biofilm formation. On the basis of these results, we further concluded that the actual negative regulator is phosphorylated FlmD. FlmD(D12K) is considered a phosphorylation activated variant. The inhibition of FlmD(D12K) on biofilm formation was consistent with expected. Hence, FlmD(D12K) is similar to CheY(D13K) and is equivalent to FlmD-P. 

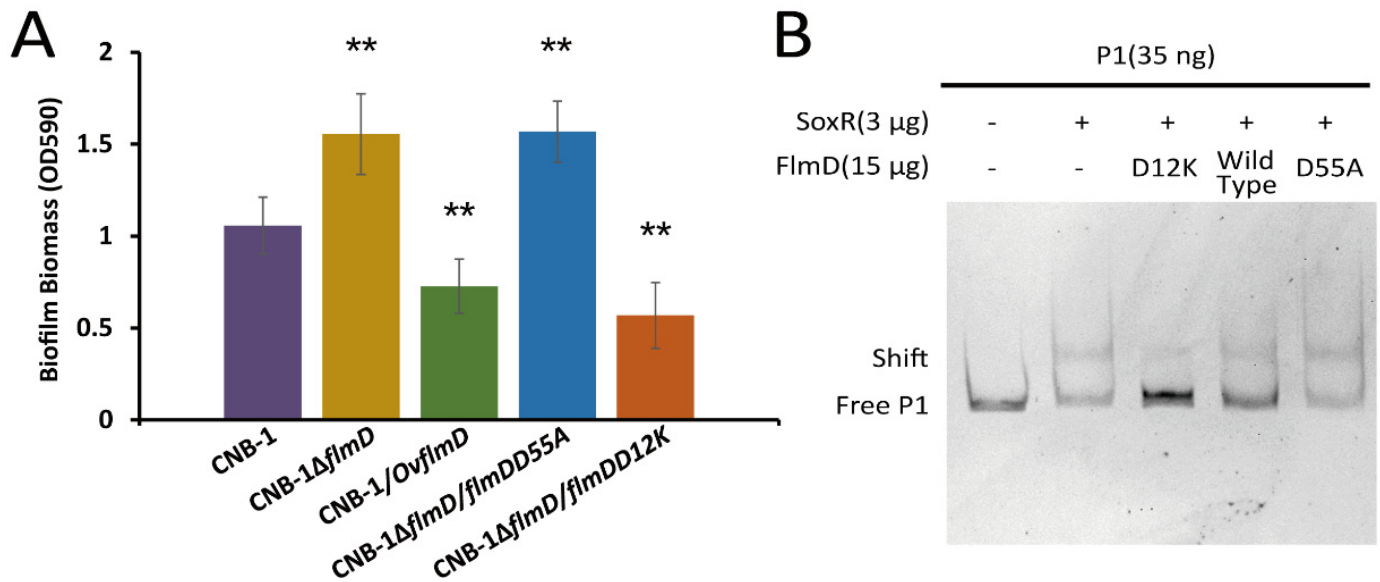

Figure 4. The phosphorylation of FlmD is essential for negative regulation. (A) Functional characterization of biofilm formation in $\mathrm{flmD}$ mutants assessed using crystal violet assay. (B) Changes in the interaction between SoxR and the $a c r A B$-tolC operon on the addition of FlmD variants to gel shift assay systems are shown. Data in panel A are the means and standard deviations from three independent experiments conducted in triplicate. ( ${ }^{* *} p<0.01$ with Student's $t$-test or rank sum test.).

As mentioned above, both FlmD and SoxR could regulate the transcription of the acrAB-tolC operon. In order to unravel the relationship between FlmD and SoxR, we assessed the effect of FlmD on SoxR in a gel shift assay system. The result showed the presence of FlmD(D12K) disrupted the interaction between SoxR and probe1 DNA, and the effect of FlmD(D12K) on SoxR was concentration-dependent (Figure 4B and Supplementary Figure S3A). Whereas FlmD(D55A) at any concentration did not affect SoxR (Figure 4B and Supplementary Figure S3B). This finding is consistent with the result that phosphorylated FlmD is the signal output.

\subsection{The Interaction between FlmD and SoxR}

The present study revealed that FlmD affected the transcriptional regulation of the acrAB-tolC operon through the transcription factor SoxR, thereby negatively regulating biofilm formation. FlmD could affect the transcriptional function of SoxR in two ways: by occupying the binding sites on DNA molecules, and by directly interacting with SoxR. However, the gel shift assay revealed that neither FlmD nor its variant FlmD(D12K)/FlmD(D55A) could bind to the acrAB-tolC operon (Figure 5A,B). The first way was excluded. To determine the potential interaction between FlmD and SoxR, a twohybrid assay with FlmD variants FlmD(D12K) and FlmD(D55A) was used. Unexpectedly, SoxR interacted with FlmDD12K as well as FlmDD55A. However, the two-hybrid assay indicates a stronger interaction of SoxR with FlmDD12K than FlmDD55A (Figure 5C). In conclusion, the phosphorylated FlmD (FlmDD12K) had a stronger interaction with SoxR, and this tight binding between the phosphorylated FlmD and SoxR negatively affected the SoxR binding to DNA molecules. 


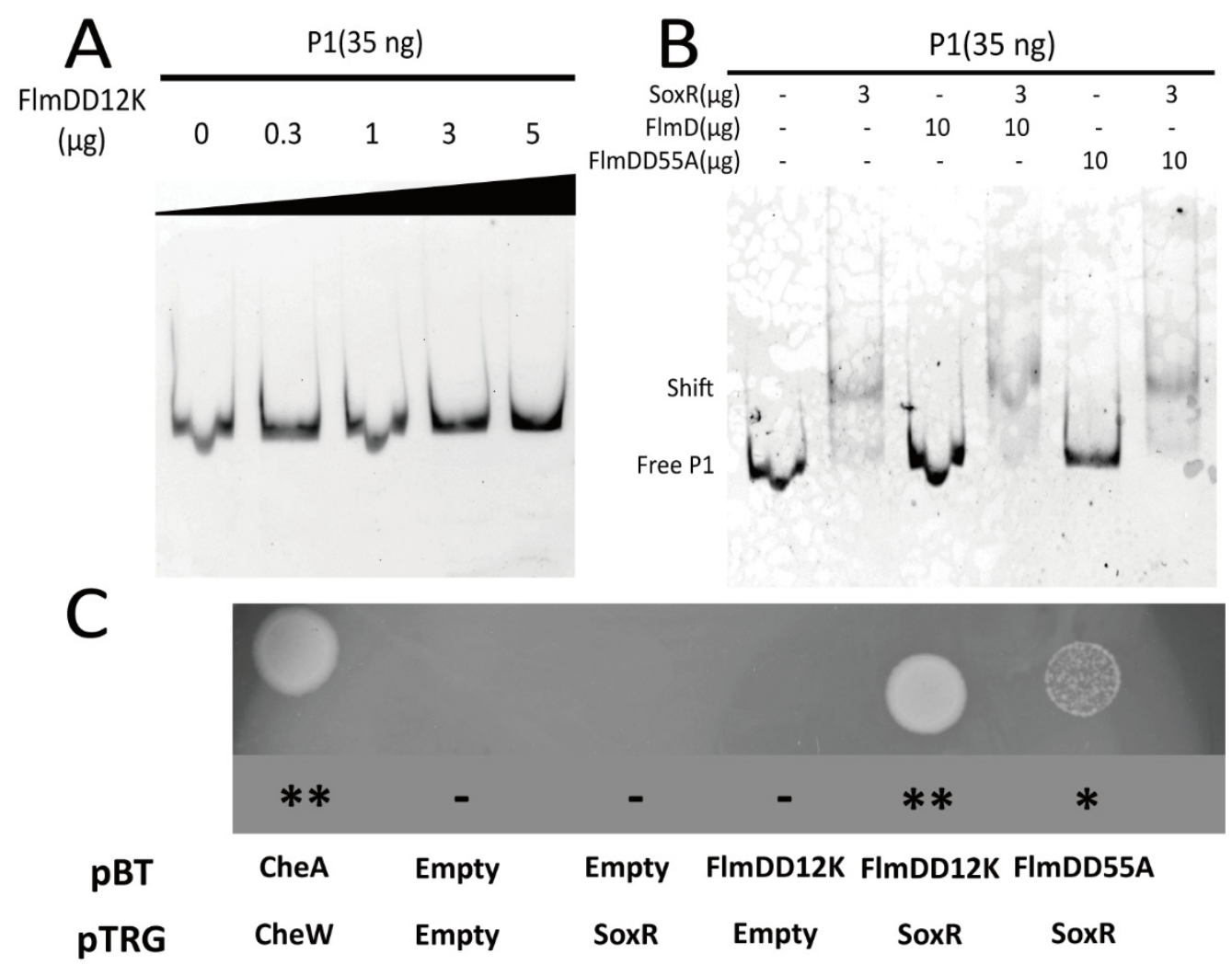

Figure 5. FlmD variant proteins interact with the transcriptional activator SoxR. (A,B) Interactions between FlmD/FlmD variants and the acrAB-tolC operon were assessed using the gel shift assay. Neither FlmDD12K nor FlmDD55A directly interacts with acrAB-tolC operon; (C) The bacterial twohybrid system measured interactions between SoxR and FlmD variants. The growth of transformants is shown on selective screening medium plates. Better growth indicates a stronger interaction. The known interaction between $\mathrm{CheA}$ and $\mathrm{CheW}$ served as positive control. The asterisk and minus indicate the growth status. ${ }^{* *}$ : strong; ${ }^{*}$ : weak; -: null.

\section{Discussion}

Signal transduction in bacterial and archaeal cells is primarily mediated by onecomponent, two-component and chemosensory systems $[9,12,46]$. Our previous study revealed two chemosensory systems (Che and Flm) in C. testosteroni. The Che pathway modulates flagellar rotation for chemotaxis, and the Flm pathway modulates biofilm formation. These two processes are coordinated through the kinase CheA and the phosphorylated response regulator FlmD [7]. In the present study, the transcriptome analysis among the wild-type and mutant strains demonstrates that FlmD negatively regulates genes in acr $A B$-tolC operon. Further sequence analysis of the acr $A B$-tolC operon shows SoxR is its transcriptional activator. FlmD, SoxR and AcrAB-TolC efflux pump are all involved in biofilm formation. These results imply both FlmD and SoxR modulate biofilm through the efflux pump. What is the relationship between FlmD and SoxR? The gel shift assay shows phosphorylated FlmD disrupts the interaction between the acr $A B$-tolC operon and SoxR. However, FlmD-P could not bind to the acrAB-tolC operon. So, FlmD-P would not occupy the binding sites of DNA molecules. In addition, the two-hybrid assay indicates the phosphorylation of FlmD enhances the interaction between the FlmD and SoxR. The interaction may have a steric effect. Phosphorylated FlmD restricts the SoxR binding to DNA molecules and inhibits the transcription of $a c r A B$-tolC operon. Overall, we identified that SoxR, a transcriptional activator of the efflux transporter acr $A B$-tolC operon, is the signal output target of FlmD. Changes in the concentrations of chemical ligands are sensed by chemoreceptors. They transmit signals to FlmA and induce its autophosphorylation. Phosphorylated FlmA transfers the phosphoryl group to cognate response regulator FlmD. 
Then, FlmD-P disrupts the interaction between SoxR and the acrAB-tolC operon, thereby inhibiting the transcription of efflux transporter genes $a c r A, a c r B$, and tolC. We also demonstrated that the AcrAB-TolC efflux pump is involved in biofilm formation; this finding is consistent with observations in other bacteria [39,40]. However, how the AcrAB-TolC efflux pump regulates biofilm formation is still unclear. Previous studies have discussed four potential mechanisms (one mechanical mechanism and three chemical mechanisms) by which AcrAB-TolC can regulate biofilm formation [38]. In addition to AcrAB-TolC, TolC is also required for the function of other efflux systems such as EmrAB-TolC and MacABTolC [47,48], which exist in C. testosteroni. Whether these efflux systems are involved in biofilm formation is unclear.

Numerous studies have reported that the regulatory network of microbial biofilms is very complex $[49,50]$. At different stages of biofilm development, the regulatory network senses different environmental signals and elicits the corresponding response [51]. Flm belongs to the chemosensory pathway, which can respond to a particular chemical stimulus depending on its associated chemoreceptors. Chemoreceptors detect various chemical signals and transmit this information into chemosensory systems [52]. Based on the gene arrangement in the $f l m$ cluster, FlmB is the associated chemoreceptor; its sensory repertoire is still unclear. However, our previous study revealed that MCP2201, which belongs to the Che pathway and senses TCA cycle intermediates [53], can transmit signals to the Flm pathway through cross-talk [7]. In other words, TCA cycle intermediates serve as chemical stimuli for regulating biofilm formation through the Flm pathway. The TCA cycle plays a central role in the metabolism of aerobic organisms. Apart from its essential role in energy generation, it provides building blocks for biosynthetic pathways [54]. Furthermore, TCA cycle intermediates are widely distributed in a variety of natural habitats. Consequently, these intermediates are suitable representatives and clues of the current nutritional status of the environment where the bacteria are located. In addition to Comamonas species, many other bacteria sense these TCA intermediates for regulating biofilm development. In Staphylococcus or Bacillus species, citrate can regulate biofilm formation [55,56]. Moreover, the MifS-MifR system of P. aeruginosa not only regulates biofilm formation but also senses alpha-ketoglutarate [57].

The Flm pathway of CNB-1 belongs to the Tfp class, but the Flm pathway controls biofilm formation instead of Tfp-based motility. Some chemosensory pathways have been reported that their phylogenomic classes did not match functions. In P. aeruginosa, the Che2 pathway (the F7 class) mediates the response to $\mathrm{O}_{2}$ stimulus [58]. Tfp-based motility in M. xanthus is mediated by Frz and Dif, which belong to ACF and F1, respectively [59]. Recently, the diversity of the functional regulation of chemosensory systems in bacteria has been reviewed [9]. Two hypotheses about the diversity of functional regulation have been proposed: (1) a pathway may switch its output target to obtain other functions, and (2) the function of one pathway may be replaced by another pathway $[9,60]$. Previously, we tried to explore all genomes in the genus Comamonas. Genome data for 11 Comamonas species are present in publicly available databases [13]. We found that seven of the 11 Comamonas species have $\mathrm{flm}$ clusters. Interestingly, some clusters of C. granuli and C. badia have annotated pilTs, which encodes a Tfp pilus assembly protein and are involved in twitching motility, and their other components are consistent with those of the flm cluster. The presence of pilT suggests that these clusters might regulate Tfp-based motility, and yet other components imply that they are related to $f l m$ cluster, a biofilm formation cluster. As a reasonable hypothesis, $\mathrm{flm}$ and other clusters might originate from a common ancestor, but a possible evolutionary event that happened in Comamonas genus caused the functional divergence between different clusters. SoxR replacing PilT as the signal output target of FlmD or the opposite, endowed these clusters with different functions. The shift from Tfp-based motility to biofilm formation, as exemplified by Flm and its related pathways, is an example of chemosensory pathway obtaining other functions through switching its output target. 
Supplementary Materials: The following supporting information can be downloaded at: https: / / www.mdpi.com/article/10.3390/microorganisms10020356/s1, Figure S1: The growth of acrABtolC operon mutant strains of $C$. testosteroni; Figure S2: The multiple sequence alignment of receiver domains; Figure S3. The effect of FlmD variant proteins on the interaction between SoxR and DNA.

Author Contributions: Conceptualization, Y.W., D.L., Z.H. and S.L.; methodology, Y.W.; validation, Y.W.; formal analysis, Y.W. and Z.H.; investigation, Y.W.; data curation, Y.W. and Z.H.; writingoriginal draft preparation, Y.W.; writing-review and editing, Y.W., Z.H. and S.L.; supervision, N.Z., C.J., D.L., C.L. and S.L.; project administration, N.Z., C.J., D.L., C.L. and S.L.; funding acquisition, S.L. All authors have read and agreed to the published version of the manuscript.

Funding: This research was funded by the Ministry of Science and Technology of the People's Republic of China (2019YFA0905500).

Institutional Review Board Statement: Not applicable.

Informed Consent Statement: Not applicable.

Data Availability Statement: The RNA-Seq data are submitted to the NCBI BioProject database (Project Accession No: PRJNA393537). All other data generated or analyzed during this study are included in this published article (and its Supplementary Information Files).

Acknowledgments: We thank Public Technology Service Center, Institute of Microbiology, CAS for their reliable technical support.

Conflicts of Interest: The authors declare that there are no competing interests.

\section{References}

1. Masak, J.; Cejkova, A.; Schreiberova, O.; Rezanka, T. Pseudomonas biofilms: Possibilities of their control. FEMS Microbiol. Ecol. 2014, 89, 1-14. [CrossRef]

2. Mah, T.F.; Pitts, B.; Pellock, B.; Walker, G.C.; Stewart, P.S.; O'Toole, G.A. A genetic basis for Pseudomonas aeruginosa biofilm antibiotic resistance. Nature 2003, 426, 306-310. [CrossRef] [PubMed]

3. Lewis, K. Persister cells. Annu. Rev. Microbiol. 2010, 64, 357-372. [CrossRef] [PubMed]

4. Mah, T.F.; O'Toole, G.A. Mechanisms of biofilm resistance to antimicrobial agents. Trends Microbiol. 2001, 9, 34-39. [CrossRef]

5. Hall-Stoodley, L.; Costerton, J.W.; Stoodley, P. Bacterial biofilms: From the natural environment to infectious diseases. Nat. Rev. Microbiol. 2004, 2, 95-108. [CrossRef] [PubMed]

6. Koshland, D.E. Response regulator model in a simple sensory system. Science 1977, 196, 1055-1063. [CrossRef]

7. Huang, Z.; Wang, Y.H.; Zhu, H.Z.; Andrianova, E.P.; Jiang, C.Y.; Li, D.F.; Ma, L.Y.; Feng, J.; Liu, Z.P.; Xiang, H.; et al. Cross talk between chemosensory pathways that modulate chemotaxis and biofilm formation. mBio 2019, 10, e02876-18. [CrossRef]

8. Moine, A.; Agrebi, R.; Espinosa, L.; Kirby, J.R.; Zusman, D.R.; Mignot, T.; Mauriello, E.M. Functional organization of a multimodular bacterial chemosensory apparatus. PLoS Genet. 2014, 10, e1004164. [CrossRef]

9. Gumerov, V.M.; Andrianova, E.P.; Zhulin, I.B. Diversity of bacterial chemosensory systems. Curr. Opin. Microbiol. 2021, 61, 42-50. [CrossRef]

10. Wadhams, G.H.; Armitage, J.P. Making sense of it all: Bacterial chemotaxis. Nat. Rev. Mol. Cell Biol. 2004, 5, 1024-1037. [CrossRef]

11. Matilla, M.A.; Martin-Mora, D.; Gavira, J.A.; Krell, T. Pseudomonas aeruginosa as a model to study chemosensory pathway signaling. Microbiol. Mol. Biol. Rev. 2021, 85, e00151-20. [CrossRef] [PubMed]

12. Wuichet, K.; Zhulin, I.B. Origins and diversification of a complex signal transduction system in prokaryotes. Sci. Signal. 2010, 3, ra50. [CrossRef] [PubMed]

13. Wang, Y.H.; Huang, Z.; Liu, S.J. Chemotaxis towards aromatic compounds: Insights from Comamonas testosteroni. Int. J. Mol. Sci. 2019, 20, 2701. [CrossRef] [PubMed]

14. Liu, L.; Zhu, W.T.; Cao, Z.; Xu, B.A.; Wang, G.J.; Luo, M.Z. High correlation between genotypes and phenotypes of environmental bacteria Comamonas testosteroni strains. BMC Genom. 2015, 16, 110. [CrossRef] [PubMed]

15. Hosaka, M.; Kamimura, N.; Toribami, S.; Mori, K.; Kasai, D.; Fukuda, M.; Masai, E. Novel tripartite aromatic acid transporter essential for terephthalate uptake in Comamonas sp. strain E6. Appl. Environ. Microbiol. 2013, 79, 6148-6155. [CrossRef]

16. Liu, L.; Jiang, C.Y.; Liu, X.Y.; Wu, J.F.; Han, J.G.; Liu, S.J. Plant-microbe association for rhizoremediation of chloronitroaromatic pollutants with Comamonas sp. strain CNB-1. Environ. Microbiol. 2007, 9, 465-473. [CrossRef]

17. Kertesz, M.A. Riding the sulfur cycle-metabolism of sulfonates and sulfate esters in gram-negative bacteria. FEMS Microbiol. Rev. 2000, 24, 135-175.

18. Arrigo, K.R. Marine microorganisms and global nutrient cycles. Nature 2005, 437, 349-355. [CrossRef]

19. Boyd, C.D.; O'Toole, G.A. Second messenger regulation of biofilm formation: Breakthroughs in understanding c-di-GMP effector systems. Annu. Rev. Cell Dev. Biol. 2012, 28, 439-462. [CrossRef] 
20. Guvener, Z.T.; Harwood, C.S. Subcellular location characteristics of the Pseudomonas aeruginosa GGDEF protein, WspR, indicate that it produces cyclic-di-GMP in response to growth on surfaces. Mol. Microbiol. 2007, 66, 1459-1473. [CrossRef]

21. Corral-Lugo, A.; De la Torre, J.; Matilla, M.A.; Fernandez, M.; Morel, B.; Espinosa-Urgel, M.; Krell, T. Assessment of the contribution of chemoreceptor-based signalling to biofilm formation. Environ. Microbiol. 2016, 18, 3355-3372. [CrossRef] [PubMed]

22. Hickman, J.W.; Tifrea, D.F.; Harwood, C.S. A chemosensory system that regulates biofilm formation through modulation of cyclic diguanylate levels. Proc. Natl. Acad. Sci. USA 2005, 102, 14422-14427. [CrossRef] [PubMed]

23. Whitchurch, C.B.; Leech, A.J.; Young, M.D.; Kennedy, D.; Sargent, J.L.; Bertrand, J.J.; Semmler, A.B.T.; Mellick, A.S.; Martin, P.R.; Alm, R.A.; et al. Characterization of a complex chemosensory signal transduction system which controls twitching motility in Pseudomonas aeruginosa. Mol. Microbiol. 2004, 52, 873-893. [CrossRef] [PubMed]

24. Fulcher, N.B.; Holliday, P.M.; Klem, E.; Cann, M.J.; Wolfgang, M.C. The Pseudomonas aeruginosa Chp chemosensory system regulates intracellular cAMP levels by modulating adenylate cyclase activity. Mol. Microbiol. 2010, 76, 889-904. [CrossRef]

25. Wu, J.F.; Jiang, C.Y.; Wang, B.J.; Ma, Y.F.; Liu, Z.P.; Liu, S.J. Novel partial reductive pathway for 4-chloronitrobenzene and nitrobenzene degradation in Comamonas sp. strain CNB-1. Appl. Environ. Microbiol. 2006, 72, 1759-1765. [CrossRef]

26. Kovach, M.E.; Elzer, P.H.; Hill, D.S.; Robertson, G.T.; Farris, M.A.; Roop, R.M., 2nd; Peterson, K.M. Four new derivatives of the broad-host-range cloning vector pBBR1MCS, carrying different antibiotic-resistance cassettes. Gene 1995, 166, 175-176. [CrossRef]

27. Langmead, B.; Salzberg, S.L. Fast gapped-read alignment with Bowtie 2. Nat. Methods 2012, 9, 357-359. [CrossRef]

28. Anders, S.; Huber, W. Differential expression analysis for sequence count data. Genome Biol. 2010, 11, R106. [CrossRef]

29. Wang, Y.H.; Chen, H.H.; Huang, Z.; Li, X.J.; Zhou, N.; Liu, C.; Jiang, C.Y.; Li, D.F.; Liu, S.J. PapA, a peptidoglycan-associated protein, interacts with OmpC and maintains cell envelope integrity. Environ. Microbiol. 2021, 23, 600-612. [CrossRef]

30. Letunic, I.; Bork, P. 20 years of the SMART protein domain annotation resource. Nucleic Acids Res. 2018, 46, D493-D496. [CrossRef]

31. Reese, M.G. Application of a time-delay neural network to promoter annotation in the Drosophila melanogaster genome. Comput. Chem. 2001, 26, 51-56. [CrossRef]

32. Li, R.W. Metagenomics and Its Applications in Agriculture, Biomedicine, and Environmental Studies; Nova Science Publisher's: Hauppauge, NY, USA, 2011; p. xi. 458p.

33. Waterhouse, A.M.; Procter, J.B.; Martin, D.M.A.; Clamp, M.; Barton, G.J. Jalview Version 2-a multiple sequence alignment editor and analysis workbench. Bioinformatics 2009, 25, 1189-1191. [CrossRef] [PubMed]

34. Katoh, K.; Rozewicki, J.; Yamada, K.D. MAFFT online service: Multiple sequence alignment, interactive sequence choice and visualization. Brief Bioinform. 2019, 20, 1160-1166. [CrossRef] [PubMed]

35. Tatusov, R.L.; Galperin, M.Y.; Natale, D.A.; Koonin, E.V. The COG database: A tool for genome-scale analysis of protein functions and evolution. Nucleic Acids Res. 2000, 28, 33-36. [CrossRef]

36. Du, D.; Wang, Z.; James, N.R.; Voss, J.E.; Klimont, E.; Ohene-Agyei, T.; Venter, H.; Chiu, W.; Luisi, B.F. Structure of the AcrAB-TolC multidrug efflux pump. Nature 2014, 509, 512-515. [CrossRef] [PubMed]

37. Zgurskaya, H.I.; Nikaido, H. Bypassing the periplasm: Reconstitution of the AcrAB multidrug efflux pump of Escherichia coli. Proc. Natl. Acad. Sci. USA 1999, 96, 7190-7195. [CrossRef] [PubMed]

38. Alav, I.; Sutton, J.M.; Rahman, K.M. Role of bacterial efflux pumps in biofilm formation. J. Antimicrob. Chemother. 2018, 73, 2003-2020. [CrossRef] [PubMed]

39. Donner, J.; Reck, M.; Bunk, B.; Jarek, M.; App, C.B.; Meier-Kolthoff, J.P.; Overmann, J.; Muller, R.; Kirschning, A.; Wagner-Dobler, I. The biofilm inhibitor carolacton enters gram-negative cells: Studies using a TolC-deficient strain of Escherichia coli. mSphere 2017, 2, e00375-17. [CrossRef]

40. Subhadra, B.; Kim, J.; Kim, D.H.; Woo, K.; Oh, M.H.; Choi, C.H. Local repressor AcrR regulates AcrAB efflux pump required for biofilm formation and virulence in Acinetobacter nosocomialis. Front. Cell Infect. Microbiol. 2018, 8, 270. [CrossRef]

41. Murakami, S.; Nakashima, R.; Yamashita, E.; Yamaguchi, A. Crystal structure of bacterial multidrug efflux transporter AcrB. Nature 2002, 419, 587-593. [CrossRef]

42. Sa-Nogueira, I.; Mota, L.J. Negative regulation of L-arabinose metabolism in Bacillus subtilis: Characterization of the araR (araC) gene. J. Bacteriol. 1997, 179, 1598-1608. [CrossRef] [PubMed]

43. Jacob, F.; Monod, J. Genetic regulatory mechanisms in the synthesis of proteins. J. Mol. Biol. 1961, 3, 318-356. [CrossRef]

44. Jiang, M.; Bourret, R.B.; Simon, M.I.; Volz, K. Uncoupled phosphorylation and activation in bacterial chemotaxis. The 2.3 A structure of an aspartate to lysine mutant at position 13 of CheY. J. Biol. Chem. 1997, 272, 11850-11855. [CrossRef] [PubMed]

45. Alon, U.; Camarena, L.; Surette, M.G.; Aguera y Arcas, B.; Liu, Y.; Leibler, S.; Stock, J.B. Response regulator output in bacterial chemotaxis. EMBO J. 1998, 17, 4238-4248. [CrossRef] [PubMed]

46. Galperin, M.Y. A census of membrane-bound and intracellular signal transduction proteins in bacteria: Bacterial IQ, extroverts and introverts. BMC Microbiol. 2005, 5, 35. [CrossRef]

47. Lin, H.T.; Bavro, V.N.; Barrera, N.P.; Frankish, H.M.; Velamakanni, S.; van Veen, H.W.; Robinson, C.V.; Borges-Walmsley, M.I.; Walmsley, A.R. MacB ABC transporter is a dimer whose ATPase activity and macrolide-binding capacity are regulated by the membrane fusion protein MacA. J. Biol. Chem. 2009, 284, 1145-1154. [PubMed]

48. Tanabe, M.; Szakonyi, G.; Brown, K.A.; Henderson, P.J.; Nield, J.; Byrne, B. The multidrug resistance efflux complex, EmrAB from Escherichia coli forms a dimer in vitro. Biochem Biophys Res. Commun 2009, 380, 338-342. [CrossRef] 
49. Karatan, E.; Watnick, P. Signals, regulatory networks, and materials that build and break bacterial biofilms. Microbiol. Mol. Biol. Rev. 2009, 73, 310-347. [CrossRef]

50. Van Wolferen, M.; Orell, A.; Albers, S.V. Archaeal biofilm formation. Nat. Rev. Microbiol. 2018, 16, 699-713. [CrossRef]

51. Nagar, E.; Schwarz, R. To be or not to be planktonic? Self-inhibition of biofilm development. Environ. Microbiol. 2015, 17, 1477-1486. [CrossRef]

52. Ortega, A.; Zhulin, I.B.; Krell, T. Sensory repertoire of bacterial chemoreceptors. Microbiol. Mol. Biol. Rev. 2017, 81, e00033-17. [CrossRef] [PubMed]

53. Ni, B.; Huang, Z.; Fan, Z.; Jiang, C.Y.; Liu, S.J. Comamonas testosteroni uses a chemoreceptor for tricarboxylic acid cycle intermediates to trigger chemotactic responses towards aromatic compounds. Mol. Microbiol. 2013, 90, 813-823. [CrossRef] [PubMed]

54. Vuoristo, K.S.; Mars, A.E.; Sanders, J.P.M.; Eggink, G.; Weusthuis, R.A. Metabolic engineering of TCA cycle for production of chemicals. Trends Biotechnol. 2016, 34, 191-197. [CrossRef] [PubMed]

55. Shanks, R.M.Q.; Meehl, M.A.; Brothers, K.M.; Martinez, R.M.; Donegan, N.P.; Graber, M.L.; Cheung, A.L.; O’Toole, G.A. Genetic evidence for an alternative citrate-dependent biofilm formation pathway in Staphylococcus aureus that is dependent on fibronectin binding proteins and the GraRS two-component regulatory system. Infect. Immun. 2008, 76, 2469-2477. [CrossRef] [PubMed]

56. Kimura, T.; Kobayashi, K. Role of glutamate synthase in biofilm formation by Bacillus subtilis. J. Bacteriol. 2020, 202, e00120-20. [CrossRef] [PubMed]

57. Tatke, G.; Kumari, H.; Silva-Herzog, E.; Ramirez, L.; Mathee, K. Pseudomonas aeruginosa MifS-MifR two-component system is specific for alpha-ketoglutarate utilization. PLoS ONE 2015, 10, e0129629. [CrossRef] [PubMed]

58. Orillard, E.; Watts, K.J. Deciphering the Che2 chemosensory pathway and the roles of individual Che2 proteins from Pseudomonas aeruginosa. Mol. Microbiol. 2021, 115, 222-237. [CrossRef]

59. Zusman, D.R.; Scott, A.E.; Yang, Z.; Kirby, J.R. Chemosensory pathways, motility and development in Myxococcus xanthus. Nat. Rev. Microbiol. 2007, 5, 862-872. [CrossRef] [PubMed]

60. Ortega, D.R.; Yang, W.; Subramanian, P.; Mann, P.; Kjaer, A.; Chen, S.; Watts, K.J.; Pirbadian, S.; Collins, D.A.; Kooger, R.; et al. Repurposing a chemosensory macromolecular machine. Nat. Commun. 2020, 11, 2041. [CrossRef] 